\title{
Aplikasi Pengukuran Tahanan Pentanahan Untuk Pengamanan Tegangan Sentuh Dan Pelatihan Teknik Instalasi Listrik Bagi Masyarakat Desa Semparu Kecamatan Kopang Kabupaten Lombok Tengah
}

\author{
Agung Budi Muljono', I. M. A. Nrartha ${ }^{1}$, Sultan Sultan ${ }^{1}$, I. M. Ginarsa ${ }^{2}$, S. M. Al. Sasongko ${ }^{3}$ \\ ${ }^{1}$ Laboratorium Sistem Tenaga Jurusan Teknik Elektro Universitas Mataram. \\ ${ }^{2}$ Laboratorium Listrik Dasar Jurusan Teknik Elektro Universitas Mataram. \\ ${ }^{3}$ Laboratorium Sistem Telekomunikasi Jurusan Teknik Elektro Universitas Mataram
}

\section{Article history}

Received: 22 Mei 2019

Revised: 2 Agustus 2019

Accepted: 9 Agustus 2019

*Corresponding Author: Agung Budi Muljono,

Kelompok penelitian Energi dan Sistem Ketenagalistrikan, Laboratorium Sistem Tenaga, Jurusan Teknik Elektro

Universitas Mataram,

Mataram, Indonesia

Email: agungbm@unram.ac.id
Abstract: Electrical energy is one of the vital needs that cannot be separated from the needs of everyday life. In energy use, a protection in the electrical installation system is needed for safety related to electricity, among others, to avoid the danger of touch voltage. Protection intended in this electricity system is to provide a protection system to realize reliable and safe conditions, both for workers and the general public, in accordance with General Standard of Electrical Instalation PUIL 2011 and the Electricity Law of 2002. Activities are carried out in Semparu Village, Kopang District, Central Lombok Regency, through counseling, training and direct measurement of detainee detention. With the aim of providing installation techniques according to standards and grounding systems for security of installation of touch stresses that are harmful to human safety. Based on the results of the evaluation, the mean pretest score of 39.375 was 65.3 in the posttest mean or there was an increase in basic understanding and further participants by $72 \%$. The results of the grounding resistance test at the village office in Semparu with the earth tester obtained a mean yield of $4.2 \Omega$ with a post depth of $1.5 \mathrm{~m}$ with the wet soil type of the former rice field already in accordance with the PUIL 2011 standard which is smaller than $5 \Omega$.

Keywords: PUIL 2011; SNI 0225:2011; Earth Tester; Post Conductor

Abstrak: Energi listrik merupakan salah satu kebutuhan vital yang tidak dapat dilepaskan dari keperluan hidup sehari-hari. Dalam penggunaan energi diperlukan suatu perlindungan dalam sistem instalasi listrik demi keselamatan yang berhubungan dengan ketenagalistrikan (electrical safety), antara lain menghindari bahaya tegangan sentuh. Perlindungan yang dimaksudkan adalah dilengkapinya suatu sistem proteksi agar terwujud kondisi andal dan aman, baik bagi pekerja maupun masyarakat umum, sesuai dengan Persyaratan Umum Instalasi Listrik PUIL 2011 dan Undang-Undang Ketenagalistrikan tahun 2002. Kegiatan dilaksanakan di Desa Semparu, Kecamatan Kopang, Kabupaten Lombok Tengah, melalui penyuluhan, pelatihan dan pengukuran tahanan pentanahan secara langsung, bertujuan memberikan keahlian teknik instalasi sesuai standar dan sistem pentanahan keamanan instalasi dari tegangan sentuh yang berbahaya bagi keselamatan manusia. Hasil evaluasi menunjukkan nilai pretest 39,375 menjadi 65,3 pada postest atau terjadi peningkatan pemahaman dasar dan lanjut peserta sebesar $72 \%$. Hasil pengujian tahanan pentanahan di kantor desa Senparu dengan earth tester diperoleh rerata hasil $4.2 \Omega$ dengan kedalaman pasak 1.5 $\mathrm{m}$ dengan tipe tanah basah bekas sawah sudah sesuai dengan standar PUIL 2011 yaitu lebih kecil dari $5 \Omega$.

Kata Kunci: PUIL 2011; SNI 0225:2011; Earth Tester; Batang Konduktor 


\section{PENDAHULUAN}

Energi listrik merupakan salah satu kebutuhan manusia yang sangat penting dan vital yang tidak dapat dilepaskan dari keperluan sehari-hari. Manusia hampir tidak dapat melakukan pekerjaan yang ada dengan baik ataupun memenuhi kebutuhannya tanpa bantuan listrik. Kekurangan energi listrik dapat mengganggu aktivitas manusia.

Keselamatan yang berhubungan dengan ketenagalistrikan (electrical safety) pada dasarnya adalah segala upaya atau langkah-langkah pengamanan terhadap instalasi tenaga listrik, peralatan serta pemanfaat listrik untuk mewujudkan kondisi andal dan aman, baik bagi pekerja maupun masyarakat umum. Korsleting listrik ini sebenarnya bisa dicegah dengan dua cara. Cara pertama adalah tidak melakukan perbuatan ilegal memanfaatkan arus listrik yang telah dipasang PLN. Kebanyakan saat ini kWh meter dan MCB yang telah disegel dirusak beberapa oknum tidak bertanggung jawab. Cara kedua, bila ingin menambah pemasangan instalasi listrik di dalam rumah atau tempat usaha, hendaknya dikerjakan oleh orang yang berkompeten di bidangnya, dengan memperhatikan kualitas penampang kabel yang harus disesuaikan.

Untuk itu dalam pemasangan dan pemakaian instalasi listrik tidak boleh dilakukan secara sembarangan. Ancaman ini berupa bahaya tegangan sentuh akibat tersengat aliran listrik yang bisa menyebabkan luka bakar, pingsan atau bahkan merenggut nyawa. Ancaman yang lain adalah terjadinya kebakaran peralatan listrik dan kebakaran perumahan penduduk. Oleh karena itu, sebelum seseorang memasang dan memakai suatu instalasi listrik harus memahami peraturan umum instalasi listrik dan standarisasi untuk mecapai keseragaman dalam penggunaan bahan dan cara kerja, (Van Harten dan E. Setiawan, (1986)). Peraturan ini bertujuan untuk melindungi manusia dan mengamankan peralatan dari bahaya yang mungkin ditimbulkan oleh listrik, serta menyediakan tenaga listrik yang aman dan efisien, Handoko, (1999).

Persyaratan Umum Instalasi Listrik memuat tentang ketentuan-ketentuan umum yang perlu diperhatikan agar dalam pengusahaan energi listrik menjadi aman, handal, berkualitas, dan ekonomis (SNI 0225:2011 (PUIL 2011)). Aman disini berarti bila instalasi listrik itu dimanfaatkan sesuai dengan ketentuan, tidak akan menimbulkan bahaya bagi pemakai energi listrik, bagi orang lain, bagi peralatan listrik, dan bagi lingkungan. Handal berarti pengusahaan energi listrik mempunyai tingkat kontinuitas yang tinggi (tidak sering padam). Berkualitas berarti besarnya tegangan dan frekuensi sebagai tolok ukur kualitas listrik masih dalam batas-batas toleransi yang diijinkan agar peralatan listrik dapat bekerja dengan baik. Ekonomis berarti tidak membutuhkan biaya yang berlebihan dalam pengusahaan energi listrik tersebut.

Perencanaan sistem instalasi listrik dengan sistem grounding pada suatu bangunan haruslah mengacu pada peraturan dan ketentuan yang berlaku sesuai dengan PUIL 2011 (SNI 0225:2011) dan Undang-Undang Ketenagalistrikan tahun 2002. Persyaratan umum instalasi listrik memuat ketentuanketentuan tentang pemasangan dan pemakaian peralatan instalasi yang meliputi penghantar, saklar, stop kontak, tusuk kontak, beban listrik, pengaman listrik, grounding, dan sebagainya yang didahului dengan kemampuan merencanakan dan desain instalasi listrik dan grounding yang benar sesuai standar.

Grounding atau pembumian peralatan listrik merupakan salah satu parameter yang perlu diperhatikan dalam merencanakan dan desain instalasi listrik. Secara singkat tujuan pengetanahan peralatan yaitu untuk mencegah terjadinya tegangan kejut listrik yang berbahaya untuk orang dalam daerah itu, mencegah timbulnya arus tertentu baik besarnya maupun lamanya dalam keadaan gangguan tanah tanpa menimbulkan kebakaran atau ledakan pada bangunan atau isinya dan untuk 
memperbaiki penampilan dari sistem. Cara yang digunakan untuk mengukur tahanan jenis tanah adalah dengan teknik tiga titik elektroda (three-point method) (Hutahuruk, (1991)) dimaksudkan untuk mengukur tahanan pentanahan.

Sistem pengamanan listrik bertujuan selain untuk melindungi jaringan listrik dan peralatan (beban) listrik juga untuk mencegah orang bersentuhan baik langsung maupun tidak langsung dengan bagian yang beraliran listrik. Sistem pengamanan bahaya sengatan listrik (tegangan sentuh) bagi manusia baik terhadap sentuhan langsung maupun sentuhan tidak langsung. Tegangan sentuh adalah tegangan yang terdapat diantara suatu obyek yang disentuh dan suatu titik berjarak 1 meter, dengan asumsi bahwa obyek yang disentuh dihubungkan dengan kisi-kisi pengetanahan yang berada di bawahnya.

Besar arus gangguan dibatasi oleh tahanan orang dan tahanan kontak ke tanah dari kaki orang tersebut, seperti pada Gambar 1.

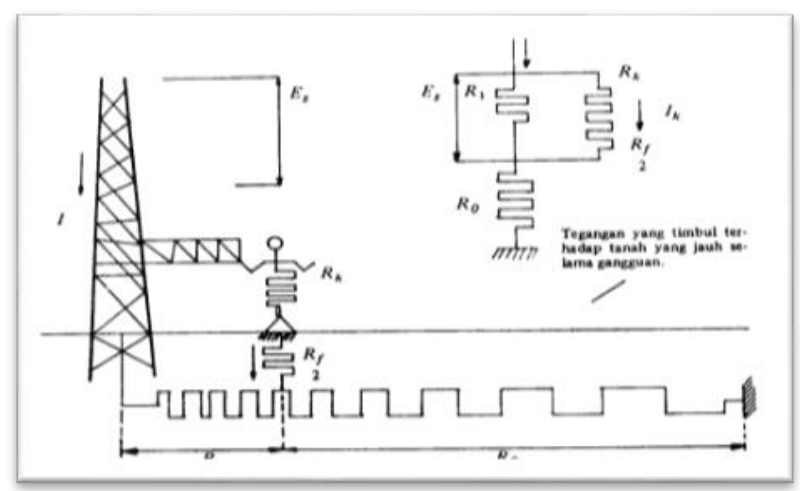

Gambar 1. Tegangan sentuh dengan rangkaian penggantinya (Hutahuruk, T.S. 1991)

Desa Semparu merupakan salah satu dari 127 desa di Lombok Tengah, dan termasuk 15 desa baru berusia 3 tahun sehingga masuk dalam katagori desa yang relatif muda, tetapi dalam kurun waktu 3 tahun Desa Semparu sudah mampu menunjukkan diri sebagai desa yang siap bersaing dengan desa lain, dan semua ini mustahil diperoleh tanpa dukungan dan kerja sama yang baik serta bahu membahu antar pemerintahan desa dengan warga masyarakat. Dalam penilaian lomba desa yang begitu sangat selektif desa Semparu muncul sebagai wakil Kabupaten Lombok Tengah untuk mengikuti lomba desa tingkat propinsi NTB, sehingga memunculkan keyakinan Wakil Bupati kalau desa semparu dapat meraih juara satu tingkat propinsi. https://kmberugakdese.wordpress.com/tag/desa-semparu/ (2017).

Dari dusun yang ada di Desa Semparu, sudah terbentuk wadah karang taruna dusun dengan melaksanakan kegiatan-kegiatan positif, antara lain peningkatan kerjasama kewirausahaan melalui berbagai pelatihan. Pelatihan yang sudah pernah dilakukan, belum pernah ada program pelatihan Pemasangan Instalasi Listrik dan grounding bagi bangunan yang aman, baik oleh karang taruna sendiri maupun oleh pihak luar. Dari hasil pengamatan di lokasi rumah penduduk, khususnya di dusun-dusun di luar jalur utama, banyak instalasi listrik yang terpasang di rumah belum memenuhi standar yang diijinkan. Demikian juga banyak cara atau penggunaan listrik yang menyalahi aturan, hal ini tidak menutup kemungkinan fungsi listrik yang harusnya bermanfaat bisa jadi malah menjadi sumber bencana, misalnya kebakaran.

Melihat permasalahan tersebut, sangat terbuka peluang bagi para dosen sebagai masyarakat akademisi untuk dapat mendekatkan tingkat intelektual kampus dengan masyarakat di luar kampus dapat menerapkan ipteks, yaitu dengan memberikan Pelatihan Teknik Instalasi Listrik dan Pengukuran 
Tahanan Pentanahan untuk Pengamanan Tegangan Sentuh bagi Masyarakat Desa Semparu, Kecamatan Kopang, Kabupaten Lombok Tengah. Kegiatan ini bertujuan mencerdaskan masyarakat dengan memberikan pengetahuan dan keahlian teknik di bidang instalasi dan keamanan instalasi dengan pemasangan pentanahan yang sesuai standar.

\section{METODE}

Kegiatan ini dilaksanakan dengan metode ceramah, peragaan, diskusi, tanya jawab, pengukuran dan penjelasan langsung di lapangan. Metode yang digunakan dalam kegiatan pengabdian masyarakat ini adalah:

\section{a. Survei awal}

Kegiatan ini didahului dengan melakukan suatu orientasi lapangan untuk mendapatkan data tentang keadaan penduduk dan mengamati instalasi listrik pada beberapa rumah penduduk. Hasil observasi awal rencana kegiatan program ini sangat dibutuhkan dan diharapkan dapat dilaksanakan di desa Semparu. Hal ini diteruskan dengan perijinan melakasanakan kegiatan kepada Kepala Desa Semparu Kecamatan Kopang.

\section{b. Rancangan Materi Pelatihan}

Materi pelatihan dirancang sedemikian rupa, dilengkapi dengan contoh-contoh dan gambar sehingga dapat dengan mudah dipahami oleh peserta berupa slide power point. Materi pelatihan yang diberikan adalah meliputi pengetahuan dasar tentang instalasi listrik dan sistem pentanahan (grounding) sesuai SPLN 2011 berupa modul-modul peraga beserta alat ukurnya.

\section{c. Penyajian/penyampaian Materi}

Metode ceramah/penyuluhan dan diskusi. Dengan metode ini kita menyampaikan pengetahuan tentang listrik dan bahayanya serta peraturan umum instalasi listrik rumah tinggal, serta Keamanan, Kesehatan dan Keselamatan Kerja (K3) bidang instalasi listrik rumah tangga pada masyarakat. Agar terjadi komunikasi dua arah yang baik dilakukan diskusi dengan para anggota masyarakat dengan demikian dapat diketahui sejauh mana tingkat pemahaman masyarakat terhadap materi pengabdian.

\section{d. Praktik}

Metode demonstrasi/peragaan. Dengan metode ini kita memperagakan peralatan-peralatan instalasi yang terdapat di rumah tinggal sesuai standar PUIL 2011 dengan sistem gronding dan menerangkan sistem pengamanan terhadap bahaya sengatan listrik (tegangan sentuh). Praktik dilakukan yang didampingi oleh tim dan teknisi berdasarkan kapakaran yang dimiliki masing-masing tim. Tim juga dibantu oleh 4 orang mahasiswa dalam proses persiapan, pelaksanaan dan evaluasi. Pengukuran tahanan pentanahan menggunakan tiga buah batang pentanahan dimana batang 1 yang tahanannya hendak diukur dan batang-batang 2 dan 3 sebagai batang pengetanahan pembantu yang juga belum diketahui tahanannya, seperti pada Gambar 2,

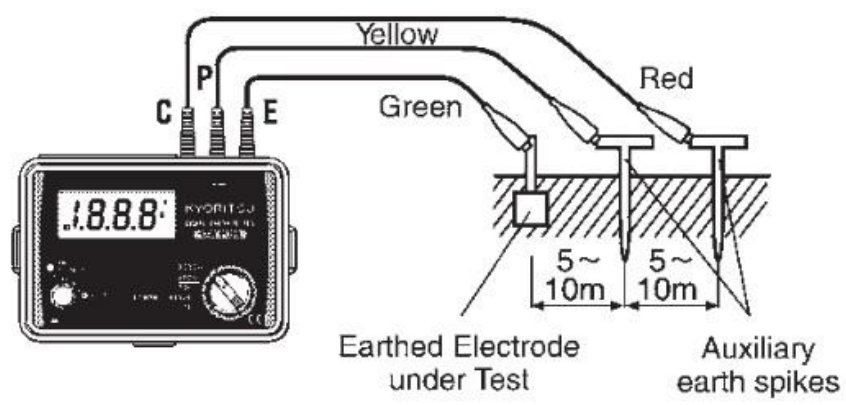

Gambar 2. Rangkaian pengukuran tahanan pentanahan metode tiga titik, (Kyoritsu. 2012) 


\section{e. Evaluasi}

Evaluasi dilakukan guna mengukur tingkat keberhasilan peserta selama mengikuti pelatihan. Evaluasi dilakukan dengan ujian teori dengan cara tertulis dan pengamatan praktik pemasangan instalasi listrik yang benar dilengkapi grounding system dan pengukuran tahanan pentanahan menggunakan digital earth tester Kyoritsu tipe 4105A.

Tahapan-tahapan pelaksanaan kegiatan ini, dapat digambarkan dalam sebuah bagan kerangka pemecahan masalah sebagai berikut seperti pada Gambar 3.

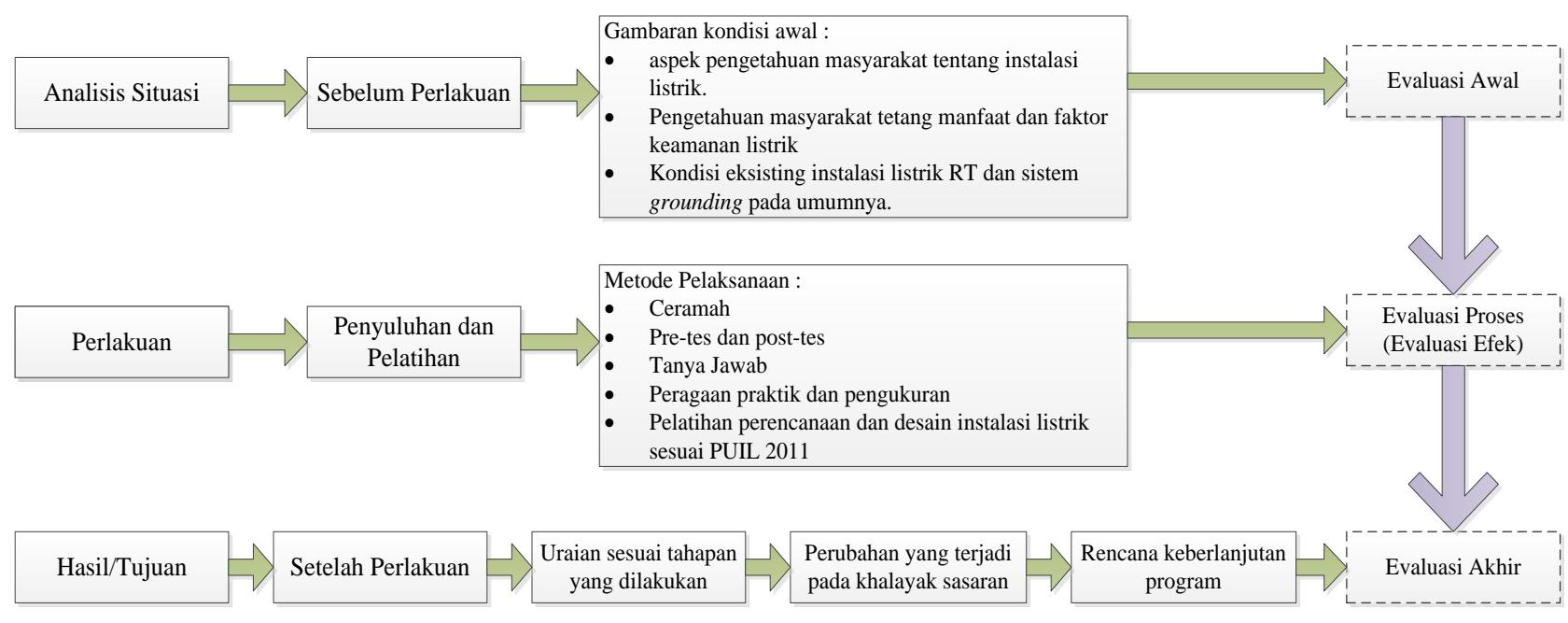

Gambar 3. Bagan kerangka pemecahan masalah

\section{Survei awal}

\section{HASIL DAN PEMBAHASAN}

Desa Semparu adalah salah satu desa yang termasuk dalam wilayah di Kecamatan Kopang Kabupaten Lombok Tengah dengan posisi geografis $08^{\circ} 36^{\prime} 1^{\prime \prime}$ Lintang Selatan dan $116^{\circ} 20^{\prime} 20.9^{\prime \prime}$ Bujur Timur. Desa Semparu merupakan salah satu dari 11 desa yang ada di kecamatan Kopang yang merupakan pemekaran dari desa Muncan pada tahun 2010. Desa Semparu resmi beridiri pada tanggal 26 Juni 2010 berdasarkan Perda Lombok Tengah Nomor 9 Tahun 2010 tentang Pembentukan Desa Semparu dan Desa Aik Bual Kecamatan Kopang. Dengan luas wilayah dan jumlah penduduk yang relatif sedikit yaitu : luas wilayah desa Semparu adalah 74,79 hektar dengan jumlah penduduk 1.091 KK dan 3.566 Jiwa, Sejak ditetapkannya desa Semparu sebagai desa yang definitif roda pembangunan dimulai. Letak desa Semparu dapat dilihat dalam peta georgafis wilayah.

Survei dilaksanakan dengan berkunjung ke kantor desa Semparu pada tanggal 26 Februari 2019 dan diterima langsung oleh Kepala Desa. Dari observasi awal rencana kegiatan PkM ini sangat dibutuhkan dan akan dilaksanakan di aula kantor desa Semparu. 

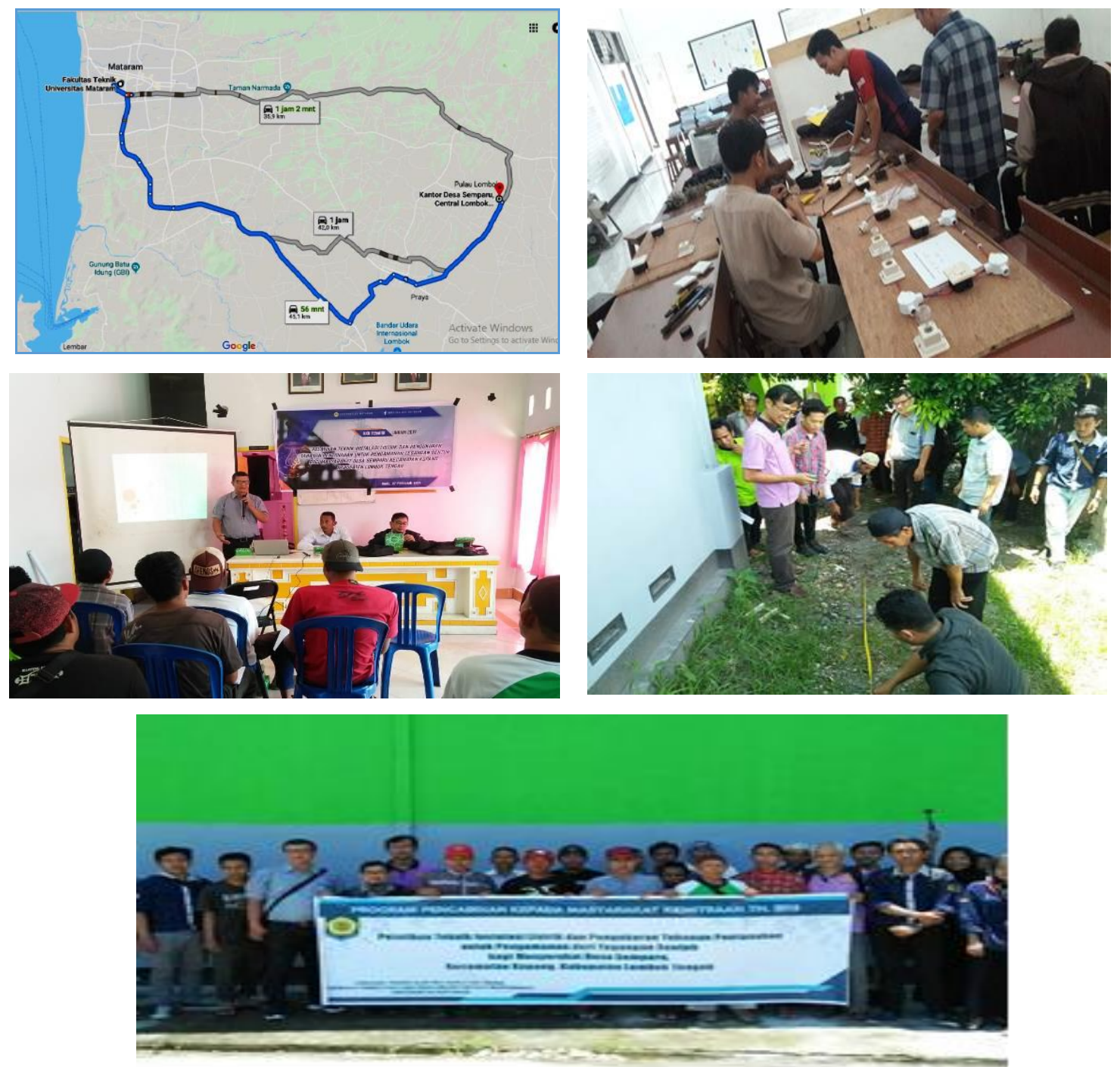

Gambar 4. Kegiatan-kegiatan PPM di Desa Semparu, sesuai arah jarum jam: Peta Akses Desa Semparu; Pembuatan Modul prototype; Pemaparan materi pelatiahan; dan Praktik pengukuran jarak elektroda, serta Peserta Pelatihan dan Tim PKM

\section{Rancangan Materi Pelatihan}

Kegiatan awal persipan materi kegiatan PkM dimulai dengan koordinasi tim dengan mengikutsertakan teknisi laboratorium dan mahasiswa Teknik Elektro konsentrasi Sistem Tenaga yang membantu dari persiapan pembuatan materi pelatihan, pelaksanaan sampai evaluasi hasil pelatihan. Kegiatan ini dilaksanakan di Laboratorium Sistem Tenaga pada bulan Maret 2019. Modul yang dipersiapkan untuk pelatihan terdiri dari dua jenis modul. Modul pertama berupa materi pelatihan dalam bentuk teori/slide (power point). Modul kedua adalah modul fisik model atau prototipe instalasi yang standar untuk instalasi stop kontak, saklar tunggal, seri, tukar dan silang, dan sistem pentanahaan untuk keamanan sistem pengaman tegangan sentuh yang berbahaya bagi manusia.

Mahasiswa membantu membuat modul-modul pelatihan tersebut seperti modul untuk contoh kabel-kabel standar instalasi listrik dan prototipe instalasi yang standar untuk instalasi stop kontak, saklar tunggal. adalah modul yang siap digunakan untuk penyuluhan/sosialisasi. 


\section{Pelaksanaan Penyajian/penyampaian Materi}

Program pelatihan dibuka oleh mitra Kepala Desa Desa Semapru, Kecamatan Kopang, Kabupaten Lombok Tengah pada tanggal 24 April 2109. Pelatihan dilakukan dalam tiga tahap yaitu tahap pertama pemaparan materi Sistem Tenaga Listrik, Manfaat dan Bahaya Listrik, Standar dan Sertifikasi Tenaga Listrik, Instalasi Listrik menurut PUIL 2011, Penggunaan Alat Ukur, Instalasi Listrik Tiga Fase dan Kesehatan dan Keselamatan Kerja Listrik. Sebelum pemaparan materi peserta diberikan soal pre-test untuk mengetahui kemampuan dasar tentang materi pelatihan, yang dikuti oleh 16 warga Desa Semparu.

Perhatian peserta dalam mengikuti kegiatan ini cukup antusias. Hampir semua aktif dalam diskusi yang dilakukan, sehingga dari sini terungkap bahwa ternyata tidak banyak dari peserta yang hadir telah memahami cara-cara pemasangan instalasi listrik yang benar sesuai SNI 0225:2011, berikut bahaya yang ditimbulkannya, terutama tentang sistem pentahanan dan bahaya dan dampak tegangan sentuh bila tidak dipasang sistem grounding yang baik. Tegangan sentuh ini berdampak negatif bagi manusia bila melebihi 50 Volt pada ruang normal, dan lebih $25 \mathrm{~V}$ pada ruang lembab.

Kegiatan selanjutnya adalah memberikan materi dan langsung dipraktikkan oleh peserta secara bergiliran. Peserta merangkai dan memasang langsung instalasi listrik pada papan peraga yang sudah kita sediakan. Ketrampilan praktik secara langsung ini kita amati sebagai bahan penilaian untuk evaluasi proses kegiatan (evaluasi efek). Pada saat pelaksanaan peserta sangat antusias dalam memasang dan merangkai modul peralatan instalasi listrik terutama pada saat dikenalkan pemasangan instalasi saklar tukar atau saklar hotel (saklar tukar). Antusiame peserta saat praktik pemasangan instalai saklar tukar dan pemasangan arde untuk pentanahan di alat kWh-meter.

Tahap kedua adalah praktik pengukuran tahanan pentanahan secara langsung, dilanjutkan dengan penanaman arde sedalam 1,5 meter di kantor desa Semparu untuk perlindungan tegangan sentuh. Pengukuran tahanan pentanahan menggunakan alat ukur earth tester. Jarak arde/elektrode pentanahan diukur dari jarak 5 meter dan 10 meter. Pengukuran dilakukan dalam beberapa arah. Nilai hasil pengukuran rata-rata sebesar $4,2 \Omega$ yang merupakan tanah basah bekas persawahan. Nilai ini sudah layak untuk perlindungan tegangan sentuh pada peralatan listrik yang diketanahkan melalui arde tersebut. Pengukuran tahanan pentanahan juga dilakukan pada tipe tanah yang lain untuk mengetahui nilai tahanan pentanahannya.

\section{Evaluasi Kegiatan Program Pelatihan}

Beberapa evaluasi telah dilakukan pada pelaksanaan pelatihan seperti evaluasi kemapuan awal peserta, kemampuan peserta setelah mendapatkan materi dan evaluasi praktik yang meliputi: aktivitas diskusi, pengetahuan memilih bahan instalasi, cara mengupas kabel, cara menyambung kabel, dan penggunaan alat ukur. Proses evaluasi dilakukan dengan dua tahapan yaitu Pretest dan Postest. Kegiatan diakhiri dengan foto bersama tim Pengabdian kepada Masyarakat dan peserta bersama Kepala Desa Semparu, dengan harapan akan terjalin kerjasama lebih lanjut antara Universitas Mataram khususnya Fakultas Teknik dengan masyarakat dan karang taruna desa Semparu

Tabel 1. menunjukkan peningkatan pengetahuan dari semua peserta palatihan dengan kenaikan pengetahuan peserta sebelum dan sesudah pelatihan bervariasi dari 33\% sampai $120 \%$. Rata-rata peningkatan pengetahuan adalah $72 \%$. Ini menunjukkan pelatihan untuk pemberian materi cukup berhasil. 
Hasil evaluasi secara tertulis berupa evaluasi kemampuan awal peserta dan evaluasi kemampuan setelah pemberian materi seperti pada Tabel 1.

Tabel 1. Nilai pretest dan postest peserta

\begin{tabular}{rllrrr}
\hline No & \multicolumn{1}{c}{ Nama Peserta } & Alamat & Pretest & Postest & Kenaikan \\
\hline 1 & Lifaturrahman & Desa Semparu & 55 & 80 & $45 \%$ \\
2 & Lalu Akmal & Desa Semparu & 45 & 60 & $33 \%$ \\
3 & Marzuki & Desa Semparu & 40 & 70 & $75 \%$ \\
4 & Lalu Supizali & Desa Semparu & 35 & 55 & $57 \%$ \\
5 & Lalu Mauladani & Desa Semparu & 30 & 65 & $117 \%$ \\
6 & Usman & Desa Semparu & 40 & 70 & $75 \%$ \\
7 & Mahdi & Desa Semparu & 25 & 45 & $80 \%$ \\
8 & Lalu Samuil & Desa Semparu & 55 & 75 & $36 \%$ \\
9 & H L Ahmad Suwadi & Desa Semparu & 50 & 70 & $40 \%$ \\
10 & Rusdi & Desa Semparu & 25 & 55 & $120 \%$ \\
11 & Juniardi & Desa Semparu & 35 & 70 & $100 \%$ \\
12 & Mardan & Desa Semparu & 40 & 75 & $88 \%$ \\
13 & Lalu Imran Rosadi & Desa Semparu & 50 & 75 & $50 \%$ \\
14 & Lalu Awaludin & Desa Semparu & 30 & 55 & $83 \%$ \\
15 & Lalu Abdul Aziz & Desa Semparu & 25 & 55 & $120 \%$ \\
16 & Hairul Azmi & Desa Semparu & 50 & 70 & $40 \%$ \\
\hline Rata-rata & & 39.375 & 65.3125 & $\mathbf{7 2 \%}$ \\
\hline
\end{tabular}

\section{Kesimpulan}

\section{KESIMPULAN DAN SARAN}

Telah diupayakan peningkatan kesadaran masyarakat tentang pentingnya pemasangan dan pemeliharaan instalasi listrik dan grounding untuk keamanan dari bahaya-bahaya yang dapat terjadi seperti kebakaran dan bahaya tegangan sentuh akibat kegagalan isolasi pada manusia.

Melalui kegiatan PKM telah terjadi peningkatan kemampuan peserta dari sisi teori dan praktik. Terjadi peningkatan pemahaman dasar dan lanjut peserta sebesar $72 \%$. Pengukuran nilai tahanan pentanahan sangat dipengaruhi oleh jenis tanah, tahanan jenis tanah, kedalaman penanaman pasak/elektroda dan jumlah pasak yang dipasang, untuk pengukuran di kantor Desa Semparu diperoleh rerata tahanan pentanahan sebesar 4,2 $\Omega$ memenuhi standar SNI 0225:2011.

\section{Saran}

Kegiatan seperti ini sebaiknya dilaksanakan secara reguler sehingga keberadaan Fakultas Teknik Jurusan Teknik Elektro lebih dikenal oleh masyarakat dengan materi pendamping yang disesuaikan dengan kondisi pada saat kegiatan dilaksanakan.

\section{Ucapan Terima Kasih}

Tim pelaksana PKM mengucapkan terimakasih kepada Universitas Mataram atas bantuan dana dari sumber dana PNBP UNRAM dengan surat perjanjian No: 2131/UN18/LPPM/2019. Dan juga bagi semua pihak yang terlibat dan telah membantu kegiatan ini, 


\section{DAFTAR PUSTAKA}

Van-Harten; Setiawan, E (1986). Sterkstoom Installation I (Instalasi Listrik Arus Kuat I), diterjemahkan oleh Setiawan, E. Binacipta: Bandung.

Hutahuruk, T.S. 1991. Pengetanahan Netral Sistem Tenaga dan Pengetanahan Peralatan, Vol. 1, Ed.2. Erlangga: Jakarta.

Kyoritsu. 2012. Instruction Manual Digital Earth Resistance Tester KEW 4105A, https://www.kewltd.co.jp/files/en/manual/4105A_IM_92-2251A_E_L.pdf, diakses tgl 23 Februari 2019.

Panitia Teknis Instalasi dan Keandalan Ketenagalistrikan, 2011, SNI 0225:2011 Persyaratan Umum Instalasi Listrik 2011 (PUIL 2011), Badan Standarisasi Nasional, Jakarta.

Tim BKD Desa Semapru, 2017. Penilaian Lomba Desa Tingkat Propinsi, https://kmberugakdese.wordpress.com/tag/desa-semparu/, Berugak Dese, diakses tanggal 10 Februari 2019. 